\title{
Cultural Narcissism as an Adaptive Strategy in Contemporary Academia
}

\author{
Author: Elisabeth Julie Vargo, PhD \\ ej.vargo@outlook.com
}

This is a non-peer reviewed version of

Vargo, E. J. (2022). Organizational Narcissism as an Adaptive Strategy in Contemporary Academia. Journal of Academic Ethics, 1-10. https://doi.org/10.1007/s10805-022-09456-2

Keywords: Research Misconduct; Research Culture, Junior Researcher, Reproducibility Crisis, Open Science

\begin{abstract}
Universities around the world are undergoing a marketisation process in order to respond to consumer-oriented demands. Despite priority shifts, universities have remained traditionally hierarchical and elitist. Moreover, a new and growing generation of academic researchers has found it increasingly difficult to integrate in academia. Systems and patterns of behaviour breeding cultural narcissism, intended as a value system characterised by an investment in false selfprojections backed by Machiavellian attainment, exist and appear to thrive in academic institutions. This organizational adaptation for survival can be seen as toxic and interlinked with workplace bullying and academic misconduct. The problematics we are witnessing today in many academic settings (high percentages of mental health issues, widespread research misconduct scandals and loss of credibility of academic research) could be explained through the lens of a narcissistic culture. Amidst economic difficulties, it might seem reasonable to adopt measures aimed at increasing assets and invest in highly entrepreneurial academics who attract financial resources to universities. Yet this same strategy might be promoting and perpetuating value systems that are
\end{abstract}


undermining academic integrity, and therefore contributing to the scientific credibility crisis and failure of academic institutions.

\section{Introduction}

Universities have historically developed to serve two purposes: produce research and disseminate knowledge (Ahmed, 2016). Their inheritance from the Enlightenment has merited them the role of public interest institutions in post-industrial societies, and their research is granted status and credibility on the basis of its disinterestedness (Lynch, 2006). In the last decades however, universities around the world, public and private alike, have transitioned to becoming more like consumeroriented corporate networks, in order to respond to increasing student numbers and growing national investments (Pelletier, Kottke, \& Sirotnik, 2019; Thelin, 2011). In parallel, an exponential growth in scientific publications and the rise of teamwork to address this increasing need to produce literature have progressively characterised modern-day science. Despite these changes, the increase in the number of awarded $\mathrm{PhD}$ degrees and junior researchers has not been accompanied by a similar expansion in the number of academic positions, and there is a steadily growing number of researchers who are not able to stay within their chosen career (Milojević, Radicchi, \& Walsh, 2018).

The organizational structure of universities has not been significantly impacted by these changes either (Schulz, 2013). A new and growing generation of academic researchers has found it increasingly difficult to compete for funding with those who have already established their credentials and are well known to those assessing, advising or making funding decisions, and remain excluded from academia (Bazeley, 2003). From within academic institutions, it appears that senior researchers maintain privilege over research funding and often play a game of status to maintain and progress in their careers, while budding researchers are obliged to maintain dependent relationships with them, perpetuating a system based on power asymmetry. A growing number of opinion articles have appeared online describing this asymmetry and the survival strategies necessary to remain in academia as "toxic", "cut-throat" and "exploitative" (Dumitrescu, 2019; Muscatelli, 2020; Vargo, 2017). Considering that the majority of universities claim to foster the professional independence of junior researchers, this state of the matter appears paradoxical (Bazeley, 2003). It could be stated that the same processes producing scientific findings on the part of educational institutions are stifling the professional growth of new investigators and maintaining the status-quo of institutional hierarchies.

Organizations, such as universities, create structures and processes to reinforce and extend their sense of identity and legitimacy, and organizational members will be motivated to preserve this, as their own self-image will be derived from their social category (Duchon \& Drake, 2009). As proposed by Lemaitre (2017), the corporatization of higher education may have attracted 
professionals with pronounced narcissistic traits to academic career paths. It may well be that the same organizational culture present in universities forge these "antisocial" conducts. In an environment where prestige and marketability are becoming more central to success, it is easy to put aside traditional virtues of the academic profession, such as scientific rigour or ethical accountability, for a place under the spotlight. In this work, I aim to demonstrate that the marketisation of academia may have bred educational environments where cultural narcissism is prevalent, and where organizational narcissism serves as a survival response to the preservation of the credibility and legitimacy of educational institutions.

\section{Understanding Narcissism as an Adaptive Behavioural Pattern}

Narcissism is one of the most overused and misunderstood words of our time and has been applied to describe bad behaviour in a wide array of cultural contexts. From a psychoanalytical term coined to define the more or less pathological pursuit of the "ego-ideal" (imposed by external parameters), in the 1970 s the term "narcissism" began to be used in a variety of disciplinary contexts, and begins to be applied to represent a generation whose newly acquired leisure time and excess income is used to pursue self-fulfilment (Tyler, 2007). Nowadays, Narcissism is commonly used to describe an identity pattern characterised by: lack of empathy, grandiosity, entitlement, superficiality, admiration and validation seeking, hyper-sensitivity, rage, and a tendency to manipulate and exploit people (Lazartigues, Planche, Saint-André, \& Morales, 2007). One source of confusion derives from the idea that the narcissist is invested in itself, whereas the narcissist is in reality invested in the false self it projects on others. It has been suggested that narcissism is a coping strategy used to obtain balance between an internal need for validation and external demands (Campbell, Miller, \& Buffardi, 2010). Research has demonstrated that individuals who are highly narcissistic are more likely to prefer hierarchical organizations with prestigious positions of power in order to satisfy their need for validation (Zitek \& Jordan, 2016).

Narcissism is a trait which has been frowned upon from the early days of western civilization, as indicated by the same origin of the term (the unhappy ending of the ancient Greek myth of Narcissus). However, it has been suggested that the consumerist economic model prevalent today has created a social environment which breeds low self-esteem, and at the same time offers external validation as a solution for feelings of frustration, in line with the narcissistic strategy (Vater, Moritz, \& Roepke, 2018). It appears that cultural narcissism is strongly related to the issue of increasing consumption and consequently the preservation of economic growth. Twenge \& Campbell (2009) point out that this social-cultural model, although initially observed through their studies in the United 
States, has become progressively influential everywhere in the industrially developed and developing world.

Organizations, like people, are also interested in protecting their identity and self-esteem. The organization's self-definition is expressed through its culture, which manifests through the values, beliefs and implicit meanings of its members (Hatch \& Schultz, 2002). This identity is dynamically produced through a constant mirroring with "outsiders" perception of the organization, and coping mechanisms aimed to protect and preserve the organization's identity can be adopted (Duchon \& Drake, 2009). Hatch and Schultz (2002) suggest that organizations can become narcissistic in the intent to protect their self-esteem, and describe this condition as a dysfunction characterised by selfabsorption and self-seduction, associated with an incapacity to incorporate messages from the outside. As Ganesh posits, "a narcissistic organizational identity privileges legitimacy over accountability. The organization is more concerned with justifying its own existence than in serving the public good." (2003, page 558).

The problem with this adaptive strategy is that it may offer short-term gratification to the individual/organization embracing it, but wreaks havoc among the individuals used as mirrors to reflect the narcissists' false and idealised self (Campbell \& Campbell, 2009). Moreover, this strategy is not sustainable and demands increasing resources. In its eagerness to gain visibility and recognition in the marketplace, the organization over engages in self-reflection, at the expense of the full range of organizational stakeholders and public opinion's expectations (Hatch \& Schultz, 2002). When the ideal self is inevitably challenged (by arising problems, etc.), truth or compromise are not the priority of the narcissist/narcissistic organization, instead, the maintenance of a positive self-image is the priority, and if necessary, the narcissist/narcissistic organization lies, deceives and socially manipulates to maintain the internal status quo (Pincus \& Roche, 2011). As maintenance of the idealised self is based on deceit and covert manipulation, it is extremely difficult to contain these toxic behaviours when they are being carried out, until they reach catastrophic proportions (Vazire \& Funder, 2006).

\section{The Harms of Narcissistic Patterns in Academia}

Stein (2003) suggests that extreme organizational narcissism will possess and behave according to five principles. First, members will believe that the organization is extraordinarily special and unique, to the point of delusion. Second, the organization will be characterised by an all-powerful sense of entitlement and anything of potency will be felt to legitimately belong to it. Third, the organization 
will be convinced of being omniscient. It will believe to have access to all internal and external information relevant to the organization. Fourth, the narcissistic delusion of the organization will lead it to be dismissive of other organizations, people and information and treat them with triumphant contempt. Fifth, these attributes become pervasive to the point of permanently taking over all organizational functioning (Stein, 2003). If we apply these principles to trends viewed in contemporary academia, it is not difficult to find correspondence.

In a recent case of research misconduct dragged in the courtroom (Jashick 2019, March 26), Duke University was held responsible for a staff member's submission of fraudulent data in 60 grant reports and funding applications to U.S. agencies, and will pay a staggering $\$ 112.5$ million to the United States Government. This and many other cases of scientific fraud (e.g., Judson, 2004) are increasingly considered not exceptional to some "bad apples" within the organizational staff but symptomatic of a normalisation of narcissistic conducts in academic settings (De Fries et al., 2006). Following Hatch and Schultz's (2002) reasoning, one of the important cultural artifacts of universities (the research output), undergoes a narcissistic transformation to serve the organization's dysfunctional self-seduction. In a study exploring the characteristics of research misconduct cases carried out in North American universities (DuBois et al., 2013), it was suggested that narcissistic thinking plays a role in research misconduct. Authors repeatedly observed senior investigators thinking they could get away with misconduct, or thought they were justified in making data fit their hypotheses. They also found that wrongdoers reporting pressure to publish and obtain grant funding did not aim merely to keep their jobs with publications and grants, but to become superstars in their fields (DuBois et al., 2013). Fitting the narcissistic profile, they assume that they are entitled to continued success, and that they are entitled to exploit resources, people, and other organizations in the service of that success (Brown, 1997).

In a working environment where claimed core values revolve around mutual trust and credibility, narcissistic behaviours can be enacted whilst taking advantage of these beliefs. Workplace bullying is a common behaviour for individuals chronically incapable of feeling empathy in work contexts. The perpetrator does not understand other people's subjectivity and cannot help but victimize his/her interlocutor when frustration runs high, thus abuse becomes a possible means to achieve goals (Misawa \& Rowland, 2015). Not coincidentally, workplace bullying in academia is a growing and worrying issue (Lester, 2013). The strongly hierarchical structure of academia and the highly dependent relationships between senior staff and junior academics allow the practice to go unnoticed and discourage its reporting and mitigation, due to concerns of possible damage to the reputation of the institution (Mahmoudi, 2019). 
Work environments characterized by rankings and roles (such as Universities) are subject to attracting employees with narcissistic tendencies, especially in their leadership roles (Zitek \& Jordan, 2016). Although some individuals may appear to have the right characteristics to be successful academics amidst contemporary higher education's funding demands, integrity and selflessness may be more advantageous traits to look for in the long run survival of Universities. Understanding and addressing Narcissistic patterns should be a concern for administrators of higher education not only because they are toxic to the survival and success of the same organizations but also because they enable bullying in the workplace and are incredibly harmful to students, who will inevitably also become subject to narcissistic power struggles and eventually, will be obliged to enact the same power dynamics (Bruhn, 2008; Twale \& De Luca, 2008). Underscoring the need for administrators to thoughtfully consider the effects of organizational structure on employees' performance and satisfaction, as well as on the very types of people their organization is attracting, should be of primary importance.

Amidst an economic crisis, it might seem that the right decision is to adopt measures aimed at increasing assets, such as investing in highly entrepreneurial academics. Yet this same strategy might be attracting working styles and individuals that are undermining scientific integrity and academic working environments. Individuals with a grandiose sense of importance and a pathological lack of empathy for others can be competitive high achievers but can just as easily destroy the hardearned reputation and credibility of entire Institutions. These traits can also be extremely detrimental to learner/mentor relationships. The reputation and quality of a University are grounded in the ethicality and accountability of its members. It is possible that the reputation crisis afflicting many universities today has its roots in a narcissistic culture that continues to reward cut-throat practices and status instead of transparency and reliability (Zabrodska et al., 2011). Several researchers have found that academics view misconduct as an adaptive strategy to the strains of the workplace, confirming the notion that narcissistic adaptive systems exist in academia, (De Vries, Anderson, \& Martinson, 2006; Franzen, Rödder, \& Weingart, 2007; Holtfreter, Reisig, Pratt, \& Mays, 2019).

\section{A New Perspective on Narcissism in Academia}

In the contemporary world, organizational culture, once hidden from view, is now more open and available for scrutiny to anyone interested (Hatch \& Schultz, 2002). This makes communication among different organizational stakeholders (from managerial roles to adjunct faculty and junior researchers thriving to become part of academia, to all parties that benefit from the organization's outputs) pivotal for the survival of the system, and necessary for the maintenance of a healthy 
organizational identity. Organizations should strive to nurture and support processes that incorporate the changing stream of people who associate themselves with the organization, in order to reinforce adaptive cultural changes.

Actions aimed at reducing research misconduct often focus on early career training, but young researchers are increasingly excluded from the scientific process and have different priorities at stake. These may account for some of the existing misconduct but not all of it. In a very comprehensive survey, Kirby and Houle (2004) pointed out that many junior members of Physics departments experienced pressure from supervisors to "overlook data that did not conform to expectations". Junior members also indicated that the unethical treatment of subordinates in research was a very serious problem, i.e., abuse of graduate students by supervisors, students treated as labour and merely as vehicles for publication. In another survey exploring misconduct among mid-career and early career researchers, malpractice was deemed significantly more common among senior academics (Martinson, Anderson, \& De Vries, 2005). As pointed out by Wagena (2005), integrity depends above all on the professional commitment to truth and honesty of senior researchers, since it seems unlikely that junior researchers can have much influence in the current structure.

In the current organizational scenarios prevalent around the world, it is considerably important for senior researchers to increase their list of publications, and in many cases this may be at the expense of students and postdocs, since junior researchers are usually responsible for a major part of senior researchers' outputs (Wagena, 2005). Research integrity for the entire science enterprise and future knowledge economies requires much more attention to the scientific community as a system (DuBois et al., 2013). Efforts to reduce and prevent misconduct would be more effective if they worked with, and not against, junior researchers (Fanelli, Costas, \& Larivière, 2015). We need to find ways to tap into this undervalued resource and use it to enhance our capacity of producing unbiased and effective research.

The reproducibility crisis (Fanelli, 2018) which is affecting the sciences, may be connected to cultural narcissism increasingly present in academic settings. The crisis stems from the large and growing proportion of studies published across disciplines that have been found to be unreliable. Grand scale replication studies which have been recently carried out are pointing in the direction of hypothesizing that reproducibility issues are more connected to research conduct than random statistical error (Klein et al., 2018). Although transgressions in research conduct have prevalently been viewed as connected to junior researcher training, there is growing concern that senior members of staff are equally accountable (Bruhn, 2008; Zabrodska, Linnell, Laws, \& Davies, 2011). My own experience of collaborating in efforts to replicate research have shown a general resistance towards 
these practices on the part of established academics, although opposing replication would paradoxically be contrary to the core principles of scientific rigour.

Ethics is an integral part of the mission and culture of colleges and universities. These should provide an environment where students learn about ethical conduct and moral boundaries, but also can actively practice these principles beyond (Bruhn, 2008). Activities oriented toward researchers at early stages of their careers have the highest prospects of providing long-term benefits to society and developing research systems that follow principles of responsible research and innovation (Krstić, 2015), but it is equally important to demonstrate in these systems that senior researchers are to be held just as accountable for their conduct.

\section{Conclusions}

Universities appear to be coping with contemporary economic demands through organizational narcissism, leading to multifaceted dysfunctions manifesting both within these organizations and through the cultural artifacts presented to the outside world. Recent efforts to democratise science through open access and preregistration of studies are a first step towards fostering a healthier and a more transparent system. These efforts should move towards democratising the distribution of funding and resources within research groups and projects, going beyond systems that value status and accumulation, and take advantage of the growing number of motivated young scientists left out of the system. Besides allowing more transparency and accountability, open access would allow further opportunities for scientific exploration and break the cycle of the publication "rat-race". Science should not to be a zero-sum game and novel solutions could foster a universal knowledge base for all. Early-career researchers should be the solution to a dysfunctional and elitist university hierarchy and not an unfortunate waste product.

\section{References}

Ahmed, J. U. (2016). Massification to marketization of higher education: Private university education in Bangladesh. Higher Education for the Future, 3(1), 76-92.

Bazeley, P. (2003). Defining 'early career' in research. Higher Education, 45(3), 257-279.

Brown, A. D. (1997). Narcissism, identity, and legitimacy. Academy of management Review, 22(3), 643-686. 
Bruhn, J. G. (2008). Value dissonance and ethics failure in academia: A causal connection?. Journal of Academic Ethics, 6(1), 17-32.

Campbell, W. K., \& Campbell, S. M. (2009). On the self-regulatory dynamics created by the peculiar benefits and costs of narcissism: A contextual reinforcement model and examination of leadership. Self and Identity, 8(2-3), 214-232.

Campbell, W. K., Miller, J. D., \& Buffardi, L. E. (2010). The United States and the "Culture of Narcissism": An examination of perceptions of national character. Social Psychological and Personality Science, 1, 222-229.

De Vries, R., Anderson, M. S., \& Martinson, B. C. (2006). Normal misbehavior: Scientists talk about the ethics of research. Journal of Empirical Research on Human Research Ethics, 1(1), 43-50.

DuBois, J. M., Anderson, E. E., Chibnall, J., Carroll, K., Gibb, T., Ogbuka, C., \& Rubbelke, T. (2013). Understanding research misconduct: A comparative analysis of 120 cases of professional wrongdoing. Accountability in Research, 20(5-6), 320-338.

Duchon, D., \& Drake, B. (2009). Organizational narcissism and virtuous behavior. Journal of business ethics, 85(3), 301-308.

Dumitrescu, I. (2019, November 21). Ten rules for succeeding in academia through upward toxicity. Times Higher Education. Retrieved from:

https://www.timeshighereducation.com/opinion/ten-rules-succeeding-academia-through-upwardtoxicity

Fanelli, D. (2018) Opinion: Is science really facing a reproducibility crisis, and do we need it to?. Proceedings of the National Academy of Sciences, 115(11), 2628-2631.

Fanelli, D., Costas, R., \& Larivière, V. (2015). Misconduct policies, academic culture and career stage, not gender or pressures to publish, affect scientific integrity. PloS one, 10(6), e0127556.

Franzen, M., Rödder, S., \& Weingart, P. (2007). Fraud: causes and culprits as perceived by science and the media. EMBO reports, 8(1), 3-7.

Ganesh, S. (2003). Organizational narcissism: Technology, legitimacy, and identity in an Indian NGO. Management Communication Quarterly, 16(4), 558-594.

Hatch, M. J., \& Schultz, M. (2002). The dynamics of organizational identity. Human relations, 55(8), 989-1018. 
Holtfreter, K., Reisig, M. D., Pratt, T. C., \& Mays, R. D. (2019). The perceived causes of research misconduct among faculty members in the natural, social, and applied sciences. Studies in Higher Education, 1-13.

Jashick, S. 2019, March 26. Duke Pays \$112M to Settle Research Misconduct Case. Retrieved from https://www.insidehighered.com/quicktakes/2019/03/26/duke-pays-112m-settle-research$\underline{\text { misconduct-case }}$

Judson, H. F. (2004). The Great Betrayal: Fraud in Science. Orlando, FL: Harcourt.

Kirby, K., \& Houle, F. A. (2004). Ethics and the Welfare of the Physics Profession. Physics Today, $57,42-47$.

Klein, R. A., Vianello, M., Hasselman, F., Adams, B. G., Adams Jr, R. B., Alper, S., \& Batra, R. (2018). Many Labs 2: Investigating variation in replicability across samples and settings. Advances in Methods and Practices in Psychological Science, 1(4), 443-490.

Krstić, S. B. (2015). Research integrity practices from the perspective of early-career researchers. Science and Engineering Ethics, 21(5), 1181-1196.

Lazartigues, A., Planche, P., Saint-André, S., \& Morales, H. (2007). New society, new families: a new basic personality? From the neurotic to the narcissistic-hedonistic personality. L'Encephale, 33(3 Pt 1), 293-299.

Lester, J. (Ed.). (2013). Workplace Bullying in Higher Education. Routledge.

Lemaitre, B. (2017). Science, narcissism and the quest for visibility. The FEBS journal, 284(6), 875-882.

Lynch, K. (2006). Neo-liberalism and marketisation: The implications for higher education. European Educational Research Journal, 5(1), 1-17.

Mahmoudi, M. (2019). Academic bullies leave no trace. BioImpacts, 9(3), 129-130.

Martinson, B. C., Anderson, M. S., \& De Vries, R. (2005). Scientists behaving badly. Nature, 435(7043), 737.

Milojević, S., Radicchi, F., \& Walsh, J. P. (2018). Changing demographics of scientific careers: The rise of the temporary workforce. Proceedings of the National Academy of Sciences, 115(50), 1261612623. 
Misawa, M., \& Rowland, M. L. (2015). Academic Bullying and Incivility in Adult, Higher, Continuing, and Professional Education. Adult Learning, 26(1), 3-5.

Muscatelli, A. (2020, January 15). Universities must overhaul the toxic working culture for academic researchers. The Guardian, Education. Retrieved from:

https://www.theguardian.com/education/2020/jan/15/universities-must-overhaul-the-toxic-workingculture-for-academic-researchers

Pelletier, K. L., Kottke, J. L., \& Sirotnik, B. W. (2019). The toxic triangle in academia: A case analysis of the emergence and manifestation of toxicity in a public university. Leadership, 15(4), 405-432.

Pincus, A. L., \& Roche, M. J. (2011). Narcissistic grandiosity and narcissistic vulnerability. Handbook of narcissism and narcissistic personality disorder, 31-40.

Schulz, J. (2013). The impact of role conflict, role ambiguity and organizational climate on the job satisfaction of academic staff in research-intensive universities in the UK. Higher Education Research \& Development, 32(3), 464-478.

Stein, M. (2003). Unbounded irrationality: Risk and organizational narcissism at long term capital management. Human Relations, 56(5), 523-540.

Thelin, J. R. (2011). A history of American higher education. JHU Press.

Tyler, I. (2007). From The Me Decade to 'The Me Millennium' The cultural history of narcissism. International Journal of Cultural Studies, 10(3), 343-363.

Twale, D. J., \& De Luca, B. M. (2008). Faculty incivility: The rise of the academic bully culture and what to do about it (Vol. 128). John Wiley \& Sons.

Vargo, E. J. (2017, October 9). A manifesto for early career researchers. Times Higher Education. Retrieved from https://www.timeshighereducation.com/blog/manifesto-early-career-researchers Vater, A., Moritz, S., \& Roepke, S. (2018). Does a narcissism epidemic exist in modern western societies? Comparing narcissism and self-esteem in East and West Germany. PloS one, 13(1), e0188287.

Vazire, S., \& Funder, D. C. (2006). Impulsivity and the self-defeating behavior of narcissists. Personality and Social Psychology Review, 10(2), 154-165. 
Wagena, E. J. (2005). The scandal of unfair behaviour of senior faculty. Journal of Medical Ethics, 31(5), 308-308.

Zabrodska, K., Linnell, S., Laws, C., \& Davies, B. (2011). Bullying as intra-active process in neoliberal universities. Qualitative Inquiry, 17(8), 709-719.

Zitek, E. M., \& Jordan, A. H. (2016). Narcissism predicts support for hierarchy (at least when

narcissists think they can rise to the top). Social Psychological and Personality Science, 7(7), 707716. 